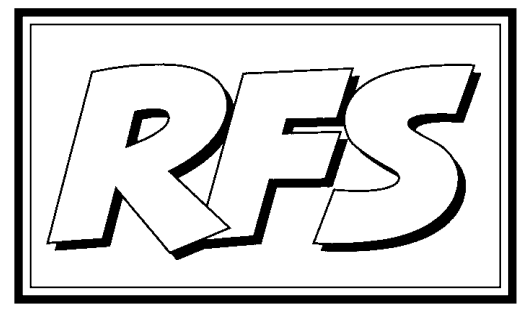

Revista de Fomento Social, 55 (2000), 47-66

\title{
Hacia un único mercado de valores en Ia Unión Europea ${ }^{1}$
}

Mateo AMBROSIO ALBALÁ*

\section{Introducción}

El comienzo de la tercera fase de la Unión Monetaria ha originado una gran cantidad de literatura sobre el tema, y especialmente en torno a los efectos macroeconómicos que la introducción de la moneda única tendrá sobre las instituciones y mercados financieros en el ámbito comunitario² .

1 Artículo elaborado a partir de una investigación presentada en junio de 1999 en el curso "Mercados e instrumentos financieros para la empresa" de la Primera Anualidad del Programa de Doctorado “Planificación, dirección y entorno económico social de la actividad empresarial", impartido durante el bienio 1998-2000 en la Facultad de Ciencias Económicas y Empresariales (ETEA), adscrita a la Universidad de Córdoba. Agradezco a Adolfo Rodero Franganillo, J oséJ uan Romero Rodríguez y Manuel Delgado Álvarez sus valiosos comentarios a la primera versión del artículo. Los errores y opiniones son de mi exclusiva responsabilidad.

* Becario de investigación del Departamento de Economía General, Ciencias Jurídicas y Sociología de la Facultad de Ciencias Económicas y Empresariales (ETEA), adscrita a la Universidad de Córdoba.

2 García Santos (1996), pág. 154. 
Se suele insistir en que la fijación irrevocable deunos tipos de cambio en las monedas, la sustitución de las monedas nacionales por el euro y la existencia de una única política monetaria incidirá sobre la estructura operativa de los mercados financieros ${ }^{3}$; lo cual no deja de ser, hasta cierto punto, bastante obvio. Igual que hablar de la eliminación del riesgo de cambio resultante de la sustitución de las monedas nacionales por una única moneda.

Sin embargo, queesto origine una mayor movilidad del capital, provoqueuna tendencia a la igualación del precio de los instrumentos financieros, acentúela competencia entre los operadores financieros, "contribuyendo al aumento de la eficiencia de la generalidad de los sistemas financieros y (...) a la gradual dilución desus rasgos específicamente nacionales" ${ }^{\text {, }}$ o "que la política monetariacomún articulada por un SEBC ${ }^{5}$ [independiente del poder político] proporcionará un entorno de crecimiento estable, sin inflación [o con ésta controlada] queatraerá el interés inversor frente al resto de países emisores" ${ }^{16}$, dependerá en gran medida de las actuaciones de los agentes y sus reacciones ante el proceso de integración monetaria y económica, entre muchos otros factores.

A la fecha de redacción de este texto, hace menos de un año que ha dado comienzo la tercera fase de la Unión Monetaria. Hay quienes afirman que "la integración culminará cuando las transacciones se realicen en una misma moneda"7. Quizás en términos políticos, esta opinión puede ser aceptable. En términos financieros, cabría esperar esta culminación sobre un horizonte más ambicioso, siemprea la espera de las reacciones en los agentes, pues no todas las dificultades en el camino hacia un mercado único de valores son de índole jurídica, política o económica. Hay características nacionales que dificultan la realización deactividades transfronterizas,

"La necesidad de familiarizarse con las condiciones de los mercados nacionales [en referencia al mercado hipotecario] dificulta la creación de productos bancarios estándar 'paneuropeos', lo que supone una barrera para la actividad transfronteriza"8

pero también se mantienen sentimientos de nacionalidad ${ }^{9}$ en los países europeos que tendrán su peso específico a la hora de lanzar una iniciativa comuni-

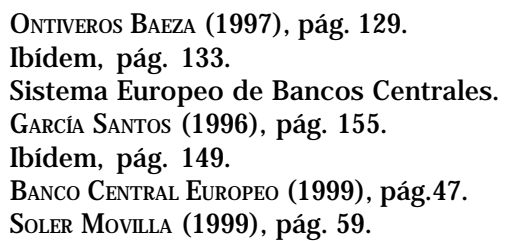


taria de mercado único de valores. En este sentido, las experiencias de los mercados de valores de alto crecimiento 0 alto riesgo EASDAQ y EURO.NM ${ }^{10}$ puede ser muy ilustrativa al respecto de qué modelo puede ser más exitoso. Sobre este punto volveremos más adelante.

Se suele afirmar que, a pesar de todos los esfuerzos realizados para la construcción de un mercado financiero integrado, el efecto sobre la industria financiera europea ha sido real mente pequeño, en cuanto que aún semantiene una estructura nacional en la provisión deservicios financieros, existen productos financieros sobrevalorados en comparación a otros países del entorno y persisten diferencias en to dos los países comunitarios en cuestiones de legalidad, fiscalidad, regulaciones y métodos de supervisión $n^{11}$.

Se plantea la existencia de distintas fuerzas que se resisten al cambio. A parte dequela industria financiera no se haya adecuado a los cambios desreguladores en un entorno macroeconómico agresivo, el papel activo desempeñado por los Estados nacionales ${ }^{12}$ ha reducido la competencia entre los países ${ }^{13}$, retrasando el desarrollo de un mercado bursátil único. Tan solo las alianzas establecidas entre las entidades intermediarias y los propios órganos rectores de los mercados, como vino a confirmar la alianza de 1997 entre las bolsas deFrancfort y Londres ${ }^{14}$, podrían entorpecer las intenciones de los Estados europeos de defender sus intereses nacionales, con todo lo que de confuso pueda tener el concepto de interés nacional en un ámbito como el financiero. Tras el surgimiento de la plataforma anglo-germana, rápidamente surgieron en nuestro país opiniones que animaban a una incorporación inmediata al proyecto:

"El acuerdo Londres-Francfort ilustra el camino a recorrer. Por lo que respecta a las plazas españolas, es absolutamente necesaria su previa integración en una plataforma de negociación y liquidación única. Después deben analizarse, con detalle pero sin pausa, las ventajas y los inconvenientes de vincularse a la plataforma única europea y decidir rápidamente la acción conveniente a la vista de sus conclusiones"15.

“... la estrategia de las restantes bolsas europeas sólo dispone de dos posibles alternativas (...). La primera de ellas es, obviamente, reproducir dicha alianza con otros mercados, quetieneel inconveniente (...) que debería incluir un número mucho

10 Para una descripción individual y comparada de estos mercados, véase Soler M OVILLA, Ma. Angeles (1999), EASDAQ y EURO.NM: mercados paneuropeos para PYMES, Actualidad Financiera, enero, pp.41-60.

11 Mccauley y White (1997), pág. 2.

12 Valero (1998), pág. 240.

13 Mccauley y White (1997), pág. 3.

14 Valero (1998), pág. 240.

15 Rodríguez Ramos (1998), pág. 20. 
más amplio de los mismos, lo cual (...) tiende a dificultar la formación y puesta en práctica de este tipo de alianzas. La otra alternativa es, desde luego, aprovechar el carácter abierto de la alianza anglo-germana y unirse a la misma tan pronto como sea posible y en las mejores condiciones que se pueda, teniendo en cuenta que (...) con toda probabilidad serán las dos bolsas de la misma las que tiendan a imponer las reglas de juego dentro de esa posible bolsa europea unificada"16

En las líneas siguientes se pond rá de relievecuáles han sido los pasos dados hasta la fecha decreación de un mercado único devalores en la Unión Europea. Nos centraremos no tanto en las autoridades comunitarias, como en las acciones desarrolladas por las propias entidades participantes y agentes de mercado, en el sentido más agregado de estos términos, al llevar a cabo acciones que hayan aprovechado y dado contenido al marco legal einstitucional establecido a través de sucesivas normas comunitarias. Para concluir el artículo, se incluye una reflexión sobre la función social de un mercado de valores, con el que se pretende recuperar un aspecto del ámbito financiero que suele ser obviado en aras de una concepción científica, funcional y pretendidamente aséptica y desideologizada de las economía.

\section{Integración financiera en el ámbito comunitario}

El origen de este proceso deintegración de los mercados europeos de valores habría que situarlo, formalmente, a comienzos de los setenta. En 1973 se aprueba la Directiva 73/183/CEE, que viene a desarrollar los principios de libertad de establecimiento y acceso a la actividad de entidades de crédito y a su ejercicio, y delibertad de prestación deservicios, ambos establecidos en el Tratado de Romajunto a la libre circulación decapitales. El desarrollo normativo posterior ${ }^{17}$ ha permitido una integración cada vez mayor entre los sistemas financierosy, en particular, entrelos mercados devalores. Varias circunstancias nos permiten hacer esta afirmación.

En primer lugar, la homogeneización del tipo de instrumentos financieros negociados. Efectivamente, entre 1985 y 1995 ha habido un desplazamiento del ahorro en todos los países de la Unión Europea de la renta fija (incluyendo los depósitos a plazo) y a corto plazo hacia seguros de vida y fondos de pensiones, acciones y fondos de inversión. Todo ello causado, en última instancia, por una reducción generalizada de los tipos de interés en el área comunitaria, pero sin

16 VALERo (1998), pág. 241.

17 Sobre la regulación comunitaria al respecto y su adaptación a la normativa española, véase García-Vaquero (1998), pp.75-79. 
obviar que la exigencia de mejores coberturas ha propiciado que las gestoras defondos de pensiones canalicen sus inversiones hacia valores más rentables.

También habría que mencionar la reducción generalizada en el número de entidades de crédito. Si en 1985 existían más de 11.200 entidades de crédito en los países que actualmente forma parte del área del euro, en abril de 1999 esta cifra no superaba las 8.250 entidades $^{18}$. Esta reducción ha resultado de un proceso deconsolidación en los sistemas bancarios nacionales, medianteunos procesos defusión y adquisición entre entidades, más que dela liquidación de las entidades existentes. A su vez estas reducciones en el número deentidades se han producido entre las cooperativas de crédito y las cajas de ahorro, mientras queel número de bancos comerciales ha crecido desde mediados de los años ochenta, debido a la creación de nuevos bancos y la transformación de algunas cajas y cooperativas de crédito en sociedades anónimas ${ }^{19}$.

Las fusiones entre entidades de países diferentes han sido comparativamente reducidas. A pesar de las expectativas que hayan podido crearse dada la legislación sobreel mercado único y la constitución dela UEM, pudieran existir casos como el proceso deadquisición del BSCH sobreel Grupo Champalimaud, de Portugal, donde los sentimientos de nacionalidad, eintereses de otraíndole, formalizados mediante vetos gubernamentales a los acuerdos privados, son antepuestos y legitimados desde el ámbito nacional frente a los compromisos adquiridos como resultado del proceso de integración financiera. En estos casos, la respuesta de Bruselas no debería dejar lugar a dudas sobre la naturaleza de la acción nacional, contraria al espíritu integracionista y transgresora de la norma establecida al respecto.

Si entreentidades de los sistemas financieros comunitarios seestán produciendo estos procesos y, paralelamente, hay una mayor homogeneización en la composición de los instrumentos financieros nacionales, en el ámbito de los mercados devalores también es posiblecomprobar el acercamiento queseestá produciendo.

En un estudio de 1997, ya se mostraba la elevada integración entre los mercad os a través de la correlación media de losíndices bursátiles elaborados por Morgan Stanley ${ }^{20}$ en al gunas plazas europeas para los períodos 1982-88 y 1988-9421 , resultando para el segundo período unas correlaciones más eleva-

18 Banco Central Europeo (1999), pág.52.

19 Ibídem.

20 Agencia internacional de calificación de riesgos. En Internet: http://www.msdwt.com/ main.htm

21 GRILLI y Dı GIORGIO (1997), pág. 19.

22 Ibídem. 
das. Esto confirmaría queel proceso de liberalización eintegración financiera ha tenido un reflejo efectivo en una mayor interrelación de los mercados europeos decapitales. En un análisis más detallado, las conclusiones obtenidas permiten afirmar que las mayores correlaciones se produjeron a finales delos ochenta y con anterioridad a la crisis del SME22.

Un estudio más reciente ${ }^{23}$ perfila aún más las relaciones existentes entre las principales bolsas dela Unión Europea. Utilizando los datos diarios delosíndices de las principales bolsas entre julio de 1995 y agosto de 1997, se observa que tanto en términos de rentabilidad como de volatilidad, los índices de los países del centro y norte delaUnión Europea presentan entresí una correlación mayor quela existenteentre los países del sur, y quela deéstos con los países del norte ${ }^{24}$.

Los movimientos conjuntos en los índices (como indicadores delas variaciones en los precios de las acciones) se ven justificados por la existencia de políticas económicas coordinadas entre los distintos países, expectativas económicas, procesos paralelos deliberalización y desregulación delos mercados, así como por otras tendencias comunes (innovaciones financieras, avances tecnológicos, importancia delos inversores institucionales, etc. $)^{25}$.

Otro circunstancia a considerar es la participación detítulos extranjeros en los mercad os de valores nacionales. A febrero de 1999 destacaba Luxemburgo, donde la práctica totalidad (99,8\%) de los títulos de renta fija negociados en su mercado pertenecían a empresas de otra nacionalidad. A gran distancia se situaban las plazas de París (29,8\%), Amsterdam (22,5\%) y Madrid (21,9\%).

En renta variable, por el contrario, tan solo en Luxemburgo y Francfort los valores deemisores foráneos superaban el $85 \%$ de los títulos negociados. En el resto de plazas, ese porcentaje no superaba el $5 \%$.

En volumen negociado, el peso de los valores foráneos es insignificante en términos porcentuales. Tan solo en el mercado deFrancfort al canzan el 10\%del total de recursos. Cercano queda el mercado de Bruselas, y algo más distante el de París, que no llega al $5 \%{ }^{26}$.

Nos encontramos, pues, en una situación donde se mantienen ciertas heterogeneidades, como hemos visto por el distinto grado de presencia de valores foráneos en los mercados nacionales, o los niveles de transposición nacional de ciertas materias legisladas a nivel comunitario. A su vez, aumenta la

23 De Miguel Colom, Ma. del Mar et al. (1998), Integración de las principales bolsas de la Unión Europea: un análisis reciente, Actualidad Financiera, julio, pp.3-21.

24 Ibídem, pág. 19.

25 Ibídem, pág. 5.

26 Cifras elaboradas sobre información disponible en http://www.fese.be/stats/stats.htm 
interrelación entre los mercados nacionales, medida por la correlación entre índices bursátiles, especialmenteentrelos mercados situados en el nortey entre los situados en el sur de la Unión. Y todo ello en un contexto en el que se profundiza la creación de un marco legislativo único, que anima a la consolidación de los sistemas financieros nacionales, y en el que se respetan directrices macroeconómicas únicas, lo que ha producido una pérdida generalizada de interés de los instrumentos de ahorro e inversión de renta fija frente a la renta variable, junto a otras opciones.

\section{Avancesen la integración institucional}

Por su parte, los avances institucionales están alcanzando otros ámbitos como son las redes de cooperación entre los mercados, los sistemas electrónicos de negociación y compensación de títulos compartidos entrelas plazas, la creación de nuevos mercados transnacionales resultado de cambios significativos en la especialización bursátil y la elaboración de familias de índices bursátiles.

Una vez homogeneizados los requisitos que debe cumplir un título para ser admitido a cotización en un mercado comunitario determinado, la existencia de sistemas comunes de negociación en varias plazas facilita, de cara a los operadores, la rapidez y fiabilidad de las operaciones ejecutadas. A modo indicativo, podríamos mencionar la Red EuroG LOBEX, en la que participan los mercados de derivados MATIF de Francia, MEFF Renta Fija de España, y desde diciembre de 1998, el mercado italiano MIF, y laRed Eurex, resultante delafusión en otoño de 1998 de los mercados de derivados de Alemania Eurex Deutschland y de Suiza Eurex Zurich, y que supuso la creación de un mercado de derivados genuinamenteeuropeo, al que recientemente seadhirió el mercado finés HEX Ltd.

Ahora bien, quevarias plazas compartan un mismo sistema denegociación, compensación y/o liquidación devalores no implicala existencia de una red de colaboración entre dichas plazas, si bien facilita cualquier intento posterior de negociación simultánea de un mismo valor. En este grupo mencionaríamos el Sistema de negociación $\mathbf{O M}$, a través de la cual los mercados de opciones y futuros de Milán (IDEM), Londres, Estocolmo, Viena y Hong Kong comparten el sistema de negociación sueco del mismo nombre; y el Sistema MEFFTRACS, desarrollado por MEFF Holding en España e implantado en otros mercados, como el Mercado de Futuros de Cítricos de Valencia, el Mercado de Futuros y Opciones de Portugal, CACOV de Caracas (Venezuela) y el WTB de Hannover (Alemania). 
En cuanto a la creación de nuevos mercados, destacaríamos dos mercados de reciente creación, pero consolidados en el segmento de las empresas jóvenes de reducidas dimensiones y con un fuerte potencial decrecimiento ${ }^{27}$ : el EASDAQ , surgido a partir dela constitución en 1994 de la Asociación Europea deIntermediarios deValores (EASD ${ }^{28}$ ), y el EURO.NM, creado en 1996 a partir de un acuerdo entre la Bolsa de Bruselas y el Nouveau Marché de la Bolsa de París.

EIEASDAQ es un mercado electrónico con sedeen Bruselas, cuyo Reglamento está adaptado a las leyes belgas -y sujeto a la Comisión Belga de Banca y Finanzas, órgano supervisor y rector de los mercados de valores en Bélgica-, aunque muy influenciado por la NASDAQ ${ }^{29}$ y la Securitiesand Exchange Comission (SEC) de los EE.UU., por la implicación de intermediarios e instituciones financieras estadounidenses en su constitución.

\section{CUADRO 1}

Distribución por nacionalidades de las empresas cotizantes en EASDAQ (en términos porcentuales)

\begin{tabular}{|lr|lr|lr|lr|}
\hline Bélgica & 22,4 & EE.UU. & 18,4 & Reino Unido 16,3 & Francia & 12,2 \\
\hline Austria & 10,2 & Holanda & 4,1 & Italia & 4,1 & Israel & 4,1 \\
\hline Liberia & 2,0 & Irlanda & 2,0 & Alemania & 2,0 & Bermudas & 2,0 \\
\hline
\end{tabular}

Fuente: www.easdaq.be; agosto de 1999. Elaboración propia.

EASDAQ es un mercado descentralizado y completamenteindependiente de cualquier otro ya existente en Ia Unión Europea; su reconocimiento como mercado de valores por la autoridad competente belga le permite, gracias a la Directiva comunitaria $22 / 1993^{30}$, el desarrollo de su actividad en cualquier otro país dela Unión, lo cual facilita el acceso a este mercado y agiliza la transmisión de información a los participantes de cualquier país comunitario. Como se

27 Como precursor de estos nuevos mercados podría considerarse el Alternative Investment Market (AIM) perteneciente a la Bolsa de Londres [Soler MoviLLA (1999), pág.50].

28 European Association of Securities Dealers, formado por un grupo de intermediarios bursátiles, empresas de capital inversión e instituciones financieras de Europa y Estados Unidos [Soler Movilla (1999), pág. 42].

29 National Association of Securities Dealer Automated Quotation de los Estados Unidos, primer mercado financiero sin ubicación física y completamente automatizado; se creó en 1971 [lbídem].

30 Directiva 93/22/CEE del Consejo, de 10 de mayo de 1993, relativa a los servicios de inversión en el ámbito de los valores negociables. 
muestra en el cuadro 1, de hecho es un mercado abierto a la negociación de valores de empresas de cualquier nacionalidad.

Por su parte, el EURO.NM se podría definir como una "confederación de mercados de ámbito nacional"31 que en la actualidad está compuesta por cuatro mercados: el Nouveau Marché de la Bolsa de París, el Neuer Markt de la Bolsa de Francfort, el NMAX de la Bolsa de Amsterdam, y el EURO.NM Belgium dela Bolsa de Bruselas ${ }^{32}$, y al que en breve se conectarán los de Copenhague, Estocolmo y Zurich ${ }^{33}$. Esta composición hace que cada mercado miembro tenga su propio reglamento, y que la supervisión y vigilancia de la actividad bursátil sea tarea respectivamente de los órganos rectores de cada Bolsa. También es un mercado abierto a empresas de distintas nacionalidades, lo que en teoría, provoca una fuerte competencia con el EASDAQ. En EURO.NM el peso del mercado alemán -en términos de capitalización bursátil- influye decisivamente en la marcha del mercado en su conjunto ${ }^{34}$.

Por el momento, el mercado más pujante es EURO.NM tanto por el número deempresas como por el volumen decontratación, si bien las diferencias entre el Neuer Markt y el Nouveau Marché y los otros dos mercados miembros son notables.

En estesentido, un aspecto interesantees el dela doble cotización dealgunas empresas, donde habría que diferenciar de un lado a las empresas que utilizan el EASDAQ para penetrar en el mercado europeo, aun cuando cotizan en otros mercados de valores (el $26,5 \%$ de las empresas que cotizan no son europeas; de las 12 empresas con doble cotización, el 70\% cotizan en el EASDAQ y el NASDAQ ${ }^{35}$, siendo de ellas 7 estadounidenses y 4 europeas). Por otro lado, tenemos a las empresas que acceden por primera vez al mercado bursátil y emiten de forma simultánea en dos mercados con el objetivo de ampliar el número de inversores al quese dirige. No habría que olvidar la vulnerabilidad

31 Soler Movilla (1999), pág. 58.

32 En un primer momento, el acuerdo de constitución de 1996 estableció unas condiciones comunes tan generales que cada uno de los mercados concretaba estas características con criterios divergentes. Por ejemplo, las condiciones de admisión a cotización en el Nouveau Marché francés exigían un volumen mínimo de 20 millones de francos franceses de activo y de 8 millones de recursos propios, mientras que en el Neuer Markt alemán no se estableció ningún límite cuantitativo. Esta situación provocó que en 1998 se firmara un nuevo Acuerdo de Armonización orientado a aumentar la convergencia, obligando a cada mercado miembro a incorporar las nuevas condiciones en sus respectivos reglamentos.

33 García Trujlllo (1999), pág.19.

34 Soler Movilla (1999), pág. 51.

35 Facilitado por la implicación del mercado NASDAQ y de la SEC estadounidense en la constitución de este mercado europeo [Soler MovilLA (1999), pág. 42]. 
delas empresas objetivo de estos mercados, más sensibles a los ciclos económicos. A este respecto, EASDAQ presenta una ventaja mayor a EURO.NM, al incluir empresas con un mayor grado de implantación en sus respectivos sectores deactividad, lo que proporcionaría una mayor confianza al inversor ${ }^{36}$.

Por último, otro tipo de asociación más peculiar es la colaboración entrelos mercados de valores para la elaboración de familias de índices bursátiles transnacionales. Entrelas principales familias deíndices bursátiles transnacionales de valores europeos, habría que destacar el Euro.NM All Share Index, el FT-SE Eurotop 100 Index y el Dow J ones Euro STOXX 50 ${ }^{37}$.

Más allá de ser meros indicadores de precios, el desarrollo de nuevos productos financieros (y en especial, delos sofisticados derivados) ha permitido la valoración y negociación de los índices bursátiles. La inclusión de valores negociados en las bases de cálculo de estos índices supondría, aparte de un excelente reconocimiento a las empresas por el desempeño en la cotización de sus títulos, un mayor peso de cada mercado en el cálculo decadaíndice, lo que vienea reforzar la posición en las sociedades encargadas de la elaboración del mismo.

\section{Manteniendo las particularidades e intereses nacionales}

El movimiento haciala integración delas bolsas europeas es un hecho. Esto no significa que existan estructuras institucionales homogéneas en los mercados nacionales de valores. Un análisis somero nos permite identificar ciertas semejanzas y diferencias en las estructuras institucionales delos mismos.

Por ejemplo, en los mercados de valores de Austria, Finlandia e Italia existe un solo órgano quegestiona tanto los segmentos de mercado orientad os a renta fija y variable como los orientados a productos derivados. Estos tres países desarrollaron en 1997 un proceso de reorganización desus respectivos mercados, lo que condujo a la transformación de cada mercado en un segmento de una única bolsa devalores. Diferentees el caso deAlemania, Bélgica y Portugal, donde los respectivos mercados de valores de renta fija y variable y el mercado de productos derivados mantienen órganos rectores diferentes. Francia y España mantienen, por su parte, una estructura muy similar, dado que los mercados de renta fija, renta variabley derivados son gestionados por sociedades independientes.

36 Soler Movilla (1999), pág. 59.

37 Para más información sobre los índices mencionados remitimos a la dirección del European Stock Market Website citado en la bibliografía. 
En el caso de los mercados de productos derivados, esta clasificación se puede incluso simplificar aún más, dado quela mayoría de los países mantiene un único mercado que englobatodos los posibles productos derivados. De los países considerados (véase cuadro 3), tan solo Francia, Italia y España mantienen dos mercados diferenciados según el activo subyacente, de un lado los índices y acciones, y del otro todos los productos relacionados con deuda pública y/o privada, divisas, tipos deinterés y commodities.

\section{CUADRO 2}

\section{Mercados europeos de productos derivados}

\begin{tabular}{|l|c|c|c|c|c|c|c|}
\hline \multirow{2}{*}{ País } & \multirow{2}{*}{ Mercado } & \multicolumn{6}{|c|}{ Activossubyacentesdelosproductosderivadosnegociados } \\
\cline { 3 - 8 } & Deuda & Acciones & Índices & Divisas & $\begin{array}{c}\text { Tiposde } \\
\text { interés }\end{array}$ & $\begin{array}{c}\text { Commo- } \\
\text { dities }\end{array}$ \\
\hline Austria & ÖTOB & $\mathrm{X}$ & $\mathrm{X}$ & $\mathrm{X}$ & & & \\
\hline Alemania & EUREX Alemania & $\mathrm{X}$ & $\mathrm{X}$ & $\mathrm{X}$ & $\mathrm{X}$ & & \\
\hline Bélgica & BELFOX & $\mathrm{X}$ & $\mathrm{X}$ & $\mathrm{X}$ & $\mathrm{X}$ & & \\
\hline Finlandia & HEX & $\mathrm{X}$ & $\mathrm{X}$ & $\mathrm{X}$ & & $\mathrm{X}$ & \\
\hline \multirow{2}{*}{ Francia } & MONEP & & $\mathrm{X}$ & $\mathrm{X}$ & & & \\
\cline { 2 - 9 } & MATIF & & & & & $\mathrm{X}$ & $\mathrm{X}$ \\
\hline \multirow{2}{*}{ Italia } & IDEM & & $\mathrm{X}$ & $\mathrm{X}$ & & & \\
\hline \multirow{2}{*}{ España } & MIF & $\mathrm{X}$ & & & & $\mathrm{X}$ & \\
\cline { 2 - 8 } & MEFF Renta Variable & & $\mathrm{X}$ & $\mathrm{X}$ & & & \\
\hline
\end{tabular}

Fuente: Elaborado en base a la información disponible en los servidores oficiales en Internet de cada mercado derivado.

Aparte de estas diferencias y semejanzas estructurales, existeuna conciencia generalizada en cuanto a la necesidad de establecer convenios con otros mercados para la negociación conjunta de valores, de abrir los mercados a nuevos valores financieros de otras economías, en definitiva, nuevas alianzas que amplíen tanto la liquidez como sobre todo el tamaño de los respectivos mercados. El caso más cercano es el Mercado de Valores Latinoamericanos en Euros (LATIBEX), que empezó a funcionar a principios de diciembre con la participación de cinco grandes empresas latinoamericanas, de las cuales cuatro son entidades financieras cuyos accionistas mayoritarios son el BBV y el $\mathrm{BSCH}$. Uno de los requisitos para cotizar en este mercado es estar previamente admitido a negociación en alguna bolsa latinoamericana, cuya normativa y 
funcionamiento sean equiparables a la de LATIBEX ${ }^{38}$.

Otro ejemplo más avanzado podría venir de las manifiestas intenciones austríacas deservir de puerta de entrada a valores de los países del Este en los mercados europeos. En este intento, el Mercado Austríaco de Opciones y Futuros (ÖTOB) está negociand o desdela primavera de 1997 opciones y futuros en dólares-y más recientementeen euros-sobreíndices devalores negociados en los mercados dela República Checa, Hungría, Polonia, Eslovaquia y Rusia, a la vez que ha elaborado un índice regional sobrevalores de los cuatro primeros países (índice CECE).

\section{Alternativas para un mercado único de valores europeo}

A la vista delas experiencias descritas, podríamos plantear hasta tres posibles modelos de mercado único de valores europeo. En todos los modelos sería necesaria una convergencia hacia sistemas comunes denegociación, compensación y liquidación, tanto informáticos como contables; se mantendrían las diversas plazas bursátiles nacionales, fortaleciend o el componente de descentralización, aunqueel papel quesele asignaría a cada una variaría de un modelo a otro. En cualquier caso, en un mercado de valores europeo no competirían entresí tan solo las empresas operantes o los valores negociados, sino también los propios mercados ${ }^{39}$.

I) Modelo centralizado: tendentehaciaun único centro relevantedeámbito europeo, cuya primeracandidata era Londres, sin olvidar a Francfort. De ahí, las airadas reacciones de las autoridades francesas ante la alianza entre ambas plazas en $1997^{40}$.

II) Modelo descentralizado autónomo: basado en el modelo deEASDAQ, un mercado independiente de cualquier centro bursátil existente en la Unión Europea, cuyo funcionamiento estaría muy ligado a las nuevas tecnologías de la información y a las directivas comunitarias, a la hora de ampliar su presencia a inversores y empresas de otros países miembros. Su reglamentación estaría afectada por la legislación existenteen el país donde se domiciliara, lo que también facilitará la relación con otros

38 Autorizado por Acuerdo del Consejo de Ministros de 29 de octubre de 1999, y completado por Orden de 10 de marzo de 2000 sobre inversiones de las instituciones de inversión colectiva en valores negociados en el Mercado de Valores Latinoamericanos. Para más información sobre este mercado, véase en Internet: http://www.latibex.com

39 Valero (1998), pág. 240.

40 Ibídem. 
mercados, dados los procesos de homogeneización legislativa que siguen los países miembros dela Unión Europea. Estaríamos hablando de un modelo en el que las plazas existentes podrían actuar como meras terminales muertas, 'portales de entrada' a ese nuevo mercado.

III) Modelo descentralizado confederado:correspondiente al modelo seguido por EURO.NM, basado en acuerdos de integración ${ }^{41}$, en los que se respetaría la personalidad jurídica de cada centro bursátil, los cuales actuarían como 'sucursales' de un mercado paneuropeo, que sería más fiel al espíritu denacionalidad existente en Europa ${ }^{42}$, y por el que inversores y empresas comunitarias podrían acceder a un mercado internacional desdesu propio mercado nacional. A su vez, ello permitiría ampliar a los intermediarios y los centros bursátiles de cada país su ámbito de actuación sin depender de una estructura supranacional que los controlara. En estesentido ya se han citado proyectos queestán cuajando con éxito: el propio mercado EURO.NM o el propio proyecto de mercado electrónico de grandes valores europeos o eurobolsa, concretado en el acuerdo de colaboración de las bolsas de París, Francfort, Bruselas, Amsterdam, Milán, Londres, Zurich y Madrid del pasado 27 denoviembre de 1998, y basado en el acuerdo inicial firmad o por los mercados británico y alemán en 1997.

Recientemente, y tras un tiempo en el que parecía queel proyecto de creación de un mercado único europeo de valores estaba en dique seco, han vuelto a aparecer noticias al respecto. El anuncio hecho por la prensa del proyecto de los grandes bancos de inversión norteamericanos de crear una nueva bolsa europea ${ }^{43}$, pareciera que ha animado a los promotores de la eurobolsa a resolver las diferencias existentes en temas como el reparto del poder y delos ingresos obtenidos a través del nuevo mercado. Estas divergencias aún parecen mantenerse. Pero sí resulta evidenteque el anuncio hecho a finales del pasado mes de septiembre de anunciar la apertura para finales del 2000 de la «Bolsa europea de grandes valores ${ }^{44}$ se podría interpretar como una reacción a las intenciones del otro lado del Atlántico.

Laidea del proyecto europeo seguiría el espíritu de lo que hemos apuntado

41 Rodríguez Ramos (1998), pág. 20.

42 SOler Movilla (1999), pág. 59.

43 «Bancos de inversión de EEUU se plantean crear una Bolsa europea», CINCO DÍAS, 14 de septiembre de 1999.

44 «a Bolsa europea de grandes valores arrancará en noviembre del 2000», CINCO DÍAS, 24 de septiembre de 1999. 
como un modelo descentralizado confederado, que supondría un modelo operativo común para los principales valores de cada mercado. Éstos mantendrían sus propios sistemas de contratación, debiend o realizar las ad aptaciones necesarias en sus propios sistemas de contratación. Otras características de este modelo de mercado sería una contratación electrónica continua y dirigida por órdenes; un acceso estándar a todos los mercados; el sistema de contratación previo y posterior a la negociación sería anónimo -en la actualidad, tan sólo en la Bolsa española es público qué intermediarios compran o venden-; funcionamiento y reglas armonizadas parala contratación continua; mecanismos de control armonizad os para evitar la manipulación del mercado o de los índices; y un acceso al mercado en igualdad de condiciones para todos los miembros, con independencia de la localización geográfica.

Hablar de integración en los mercados de valores comunitarios probablemente no sea sinónimo de mercado único; ni tan siquiera se debiera pensar que la existencia de una moneda única implique la culminación de un proceso que no acaba sino de comenzar.

\section{Epílogo: la función social de un mercado de valores}

El desarrollo de un marco legislativo e institucional apropiado para la integración de los mercados devalores tendría como principales beneficiarios directos a los agentes demandantes derecursos y a los agentes oferentes de los mismos. Para los primeros supondría una mayor oferta de recursos, lo que les permitiría diversificar las fuentes de financiación y reducir sus costes decapital. Paralos segundos, una mayor demanda de recursos, beneficioso para diversificar sus colocaciones y gestionar eficazmente una reducción del riesgo inherente a cualquier decisión de inversión. Hasta ahora todo pareceindicar quelos pasos dados en el proceso de integración financiera en la Unión Europea parecen procurar el logro de estos beneficios.

Llegad os a este punto, nos planteamos si este proceso real mentetienealgún alcance para la mayoría dela población. ¿Beneficia al ciudadano la integración de los mercados europeos devalores y el desarrollo de los principios de libertad deestablecimiento y de prestación deservicios financieros?

En la medida quela ciudadanía invierta o negocie, podráacceder a una mayor variedad de instrumentos financieros que, eficientemente negociados, les permitiráaprovechar los procesos de especulación y arbitrajeen su beneficio. Así mismo, al aparecer nuevas empresas de servicios financieros de asesoramiento y gestión de cartera, el usuario de éstos se verá beneficiado en la medida que la competencia conduzca a una reducción en los precios por el servicio 
prestado. Pero los mercados de valores no sólo benefician a quienes participan directamente en ellos. La canalización rápida y flexible de los fondos de los ahorradores a los inversores facilita los pagos eintercambios entreagentes. Esto permitela ejecución de proyectos empresariales deenorme importancia para el desarrollo económico de un país, lo quetiene efectos muy beneficiosos para el conjunto de la sociedad.

Sin embargo, el establecimiento de un marco que permita los acuerdos de colaboración entre mercados devalores, y el levantamiento de cualquier traba a la prestación de servicios financieros y al establecimiento de una empresa en otro Estado, no garantiza en absoluto los beneficios teóricos mencionados ni asegura la inexistencia de abusos para el consumidor de estos servicios. En una recientecomunicación dela Comisión ${ }^{45}$, se establecían las líneas generales de un marco deacción para la mejora de los servicios financieros. Entre las líneas señaladas, se insistía en la necesidad de "reconciliar de manera pragmática la exigencia de una integración efectiva de los mercados financieros con la de un elevado nivel de protección de los consumidores"46 , distinguiendo claramente entreusuarios deservicios financieros profesionales y no profesionales; determinando las diferencias principales entre las normativas nacionales vigentes quejustifiquen la aplicación de la mismas; y fomentando la convergencia delas prácticas nacionales hacia un nivel mayor de protección delos consumidores.

En estos tiempos en los que se aboga por la libertad económica sin más, se echa en falta una compañera de viaje que debiera ser inseparable: la responsabilidad personal. Desgraciadamente seha venido propugnando desdeel ámbito académico y profesional una concepción de los mercados de valores, entendidos como un "mundo de relaciones funcionales donde, lógicamente, la ética no tiene sentido"47. Una concepción de la economía entendida como una realidad científica, alejada de "cualquier atisbo de consideración éticofilosófica para mostrar la posibilidad de un tratamiento meramente neutral y descriptivo"48. Unido a esto, se llega a abstraer hasta tal punto las acciones de los agentes participantes en el mercado, que finalmente se diluye la responsabilidad de los mismos. En palabras deJ osé Luis Oller Ariño, Director General del MEFF, "la actividad legítima y justa deun conjunto amplio deagentes autónomos

45 Comisión Europea (1998a), Servicios financieros: construcción de un marco de acción, Comunicación de 28 de octubre de 1998. En Internet: http://europa.eu.int/scadplus/leg/es/lvb/ I24050.htm

47 Op. cit., pág. 179.

48 Ibídem. 
puede provocar resultados que aparezcan como inapropiados o indeseables y que no respondan al designio y responsabilidad de nadieen particular, por lo que tampoco cabe formular sobre ellos juicio ético"49.

En modo alguno creemos que se deban vetar los juicios éticos sobre los resultados y las acciones de los agentes, máxime cuando cualquier decisión tomada en éste ámbito siempre tendrá unas consecuencias concretas sobre accionistas, trabajadores, clientes, o consumidores, cada uno con sus particularidades. Coexisten lo macro y lo micro; la sociedad y los individuos; los mercados, las instituciones y los agentes inversores, ahorrad ores y mediadores.

Es indudable la importancia de contar con un sistema financiero eficiente para el progreso de las sociedades y en ello tiene gran importancia el papel desarrollado por los mercados de valores, precisamente por centrar su actividad en un bien tan peculiar, además deser algo más que "simples máquinas de hacer dinero" cuyas reglas de funcionamiento se conviertan en manual de simulad ores bursátiles. Un funcionamiento socialmenteeficaz y eficiente de los mercados de valores necesita no sólo de una mayor libertad económica o responsabilidad personal en los agentes ${ }^{50}$. Ante el manejo de tal cantidad de riqueza y las consecuencias que directa e indirectamente tienen sobre el conjunto de la sociedad, se requiere de reglas comúnmente aceptadas e instituciones, más que de ecuaciones, modelos estadísticos y operaciones inteligentes ${ }^{51}$.

Y es aquí dondetiene pleno sentido la afirmación hecha por la Comisión. Es necesaria una normativa que a la vez que garantiza el acceso a una información adecuada para inversores y la estabilidad y seguridad del mercado, protegea los consumidores de estos servicios, como inversores o como ahorradores. Una concepción meramente funcional del mercado de valores no trasciende más allá del establecimiento deunas reglas del juego, obviando cual quier desventaja en la situación de partida de los inversores; asumiendo dentro de la lógica del sistema las crisis einestabilidades del mercado y, sobretodo, las consecuencias que exceden el ámbito bursátil; y considerando como distorsiones o ruidos del sistema cualquier normativa que coharte la libertad de acción de los agentes participantes.

No obstante los avances legislativos comunitarios en la materia, entrelos que cabría destacar la implementación de un sistema de garantía de inversiones

49 Oller Ariño (1995), pág. 236.

50 Véase las tesis sobre las que J osé Luis Fernández desarrolla sus reflexiones en torno a la ética en el sistema financiero, en Fernández Fernández (1994), pág. 391.

51 Franch Meneu (1995), pág. 190. 
comparable al existente en el sector bancario ${ }^{52}$, siguen siendo un hecho los incumplimientos delos Estados miembros ${ }^{53}$ y los casos continuos de intermediarios participantes en los mercados, quedesarrollan su actividad mediantelos conocidos como "chiringuitos financieros".

Con esta reflexión tan sólo hemos pretendido rescatar un matiz de estos mercados quesi bien es objeto deanálisis extenso y profundo en muchos textos, creemos que no es puesto de relieve en las actuaciones de quienes regulan, negocian o participan en esos ámbitos. Alejar a los mercados de valores de cualquier "atisbo deconsideración ético-filosófica" es desvirtuar por completo un ámbito creado por y para el encuentro de la naturaleza humana, quea su vez requiere de un marco institucional y jurídico para transformar lo que hoy es razón última y fin en eseámbito, en tan solo un medio para procurar el bienestar común.

\section{ANEXO: Reinventando el crecimiento económico}

Los acontecimientos de los últimos meses han supuesto un decidido empuje en el proyecto de creación de sistemas que integren a los mercados europeos devalores en sus distintos segmentos.

Al proyecto de Euro.NM han solicitado su incorporación los mercados de Oslo y Helsinki. De igual forma, se espera que el correspondiente al nuevo mercado en Londres (o bien, un nuevo segmento que cumpla los requisitos de ingreso en el Euro.NM con mayor solvencia ${ }^{54}$ ), se integre en breve en un sistema demercado de valores que ciertamente tienen un componente continental de peso.

Nuevo impulso están viviendo otros mercados, sobretodo los especializados en valores tecnológicos y de rápido crecimiento, como son el Easdaq, el TechMARK de Londres, y el SWX New Market suizo, estos dos últimos de muy reciente creación ${ }^{55}$. El acuerdo entreFrancfort y Londres se formalizó definitivamenteen el mercado iX, por el cual Francfort asumiría el segmento devalores

52 Comisión Europea (1998b), Mercados de valores mobiliarios: situación actual y perspectivas. En Internet:http://europa.eu.int/scadplus/leg/es/lvb/l24031.htm

53 Para una relación de los casos recientes de infracción de los Estados miembros de la UE en materia de servicios financieros, véase en Internet: http://europa.eu.int/comm/dg15/en/ finances/infr/index.htm

54 Véase Die Welt-Wirtschaft, de 30 de abril de 1999 (www.welt.de/daten/1999/04/30/ 0430wi65603.htx)

55 Véase ALONSO-MAJAGRANZAS, Beatriz (2000), Mercados para empresas de alto crecimiento en Europa, La Revista de Bolsa de Madrid, no 87, abril, Bolsa de Madrid, pp.10-15. 
tradicionales y Londres, los segmentos tecnológico y de derivados. A estenuevo mercado han solicitado incorporarse los mercados de Madrid y Milán.

Y por supuesto, hay que mencionar el caso español. En menos deseis meses la Bolsa de Madrid ha liderado dos proyectos de envergadura: el Mercado de Valores Latinoamericanos en Euros (LATIBEX) ${ }^{56}$ y el de más reciente creación, el Nuevo Mercado, segmento del mercado continuo dela Bolsa de Madrid, que comenzó a operar el 10 de abril de este año $0^{57}$. Ambos son ejemplos de los dos tipos de mercados de valores dominantes en la actualidad: los mercados de valores tradicionales y los mercados de compañías de telecomunicaciones, medios y tecnología(TMT).

Si a comienzos de los noventa, la moda de los mercados financieros eran los fondos de inversión, las nuevas estrellas del mercado devalores son las empresas innovadoras en el ámbito tecnológico, que responden a las exigencias de la «nueva economía»: gran potencial de crecimiento y ganancias, unido a un riesgo muy superior al de otros sectores. La "nueva economía" se está gestando en los mercados de valores, y con ello se pretende facilitar el acceso a unas fuentes definanciación as equibles y eficaces para desarrollar proyectos empresariales de elevado potencial de crecimiento, pero con un muy alto riesgo. Este riesgo, justificado en la normativa jurídica desarrollada a la fecha como la «ncertidumbre delo novedoso», Ileva a una protección mayor del inversor que se formaliza exclusivamente mediante el requerimiento de una información más detallada sobre los factores relevantes para el desarrollo de la actividad de la empresa, los riesgos asociados a la actividad, planes futuros de inversión y financiación, y estabilidad futura de la estructura de propiedad en la empresa.

Precisamentela recientecreación dela mayoría deestos proyectos, y ciertas peculiaridades de los mismos, les impiden cumplir ciertos requisitos establecidos para su admisión a cotización en los mercados devalores tradicionales, lo que ha requerido de la creación de nuevos segmentos que les dieran cabida.

Visto el decidido apoyo que las autoridades de los países miembros de la Unión Europea prestaron en la reciente Cumbre de Lisboa a este nuevo filón

56 Véase GARRIDO, Javier (1999), Respaldo unánime a Latibex, el Mercado de valores latinoamericanos en euros, La Revista de Bolsa de Madrid, no82, noviembre, Bolsa de Madrid, pp.4-17; y SÁNCHEZ, María José (1999), Latinoamérica hoy, en: Op.cit., pp.18-25.

57 Aprobada por Orden Ministerial de 22 de diciembre de 1999 (publicado en el BOE de 30 de diciembre de 1999), y desarrollado en la Circular 1/2000 de la Comisión Nacional del Mercado de Valores (publicado en el BOE de 17 de febrero de 2000), por la que se establece las condiciones particulares de admisión y permanencia del "Nuevo Mercado". Así mismo, véase FERRÁN, Eduardo (2000), El nuevo mercado da sus primeros pasos, La Revista de Bolsa de Madrid, n8, abril, Bolsa de Madrid, pp.6-9. 
para retomar la senda del crecimiento económico, si las optimistas y renovadas expectativas provocadas por estos valores, y materializadas en elevadas y vertiginosas capitalizaciones bursátiles, no sellegan a realizar, el estallido dela "burbuja tecnológica" afectaría a algo más que las carteras de valores de los inversores. Seguramente, las amplias posibilidades deintegración quese ofrecen entre los distintos segmentos nacionales sea un aliciente más para los sobredimensionamientos que han sufrido estetipo de valores. Pero finalmente sería un gol pe a esta nueva y decidida revitalización de la idea del crecimiento económico, cuando parecía que el paso que restaba era el dela redistribución y el desarrollo. Y es que la feroz especulación que se desarrolla en estos mercados no parece servir como garantía de estabilidad a un sector en torno al cual se han creado tantas expectativas decrecimiento y generación deempleo (y no sólo de alta cualificación).

Ante este panorama, al consumidor de servicios de inversión que se ha animado a invertir en estos valores, debe asumir que no se trata tan sólo entrar en un nuevo sector económico; la velocidad a la que maduran los cambios en esta "nueva economía" no permiteequivocaciones. Tan sólo lequeda exigir una transparencia informativa que le permita tomar conciencia real del riesgo que está asumiendo.

\section{Bibliografía}

Banco Central Europeo (1999), «El sector bancario en el área del euro: características fundamentales y tendencias», Boletín mensual, A bril, Francfort.

Comisión Europea (1998a), Servicios financieros: construcción de un marco de acción, Comunicación de 28 de octubre de 1998. En Internet: http:// europa.eu.int/scadplus/leg/es/lvb/l24050.htm

Comisión EuRopea (1998b), Mercados de valores mobiliarios: situación actual y perspectivas. En Internet:http://europa.eu.int/scadplus/leg/es/lvb/I24031.htm

EUROPEAN Stock Market InDEXEs WebSITE, Austrian Traded IndexATX 50, Institute for Advanced Studies y Skandia Leben AG, Viena. En Internet: http://www.finix.at Fernández FernÁnDEZ, J.L. (1994), «Sistema financiero y problemas morales: una agenda para la reflexión ética», en Revista de Fomento Social, Núm. 49, ETEA, Córdoba, pp.387-412.

García SANTOS, N. (1996), «La integración de los mercados financieros en el marco de la Unión Monetaria», en Ekonomi Gerizan, № III, Fundación de Cajas de Ahorros Vascos-Navarras, Bilbao, pp.147-160.

García Truj ILlo, S. (1999), «Tiempos de cambio en las bolsas (II)», EL PAís- 
Negocios, 25-26 de diciembre, pág.19.

García Vaquero, V. (1998), «Oportunidades y estrategias ante el mercado único de servicios de inversión», Cua dernos de Informa ción Económica, Núm. 131, febrero, pp.73-88.

GrILLI, V. y Di GIORGIO, G. (1997), Integración financiera y monetaria europea, Estudios Bancarios, Fundación BBV, Bilbao.

MCCAULEY, R.N. y WHITE, W.R. (1997), «The euro and european financial markets», Bank of International Settlements, Working Paper no 41, J ulio, Basilea, 65 pp. Miguel Colom, Mạ.M. et al. (1998), «ntegración de las principales bolsas de la Unión Europea: un análisis reciente», Actualidad Financiera, julio, pp.3-21. OntIVERos BaEzA, E. (1997), «Los mercados financieros en la Unión Monetaria», en: Varios, Los retos de la Unión Europea ante el siglo XXI, Banco del Comercio, Madrid, pp.129-145.

Soler MoviLLA, MáÁ. ( 1999), «EASDAQ y EURO.NM: mercados paneuropeos para PYMES», Actualidad Financiera, enero, pp.41-60.

Valero, F.J. (1998), «iHacia una bolsa unificada en Europa?», Cuadernos de Información Económica, Núm. 136/137, julio/agosto, pp.240-241. 